\title{
A Multilayered Technique for Repair of the Suboccipital Retrosigmoid Craniotomy
}

\author{
Amir Goodarzi ${ }^{1} \quad$ Arjang Ahmadpour $^{1} \quad$ Atrin Toussi $^{1} \quad$ Kiarash Shahlaie $^{1}$ \\ ${ }^{1}$ Department of Neurological Surgery, University of California, Davis \\ School of Medicine, Sacramento, California, United States \\ J Neurol Surg B 2018;79:508-514. \\ Address for correspondence Kiarash Shahlaie, MD, PhD, Department \\ of Neurological Surgery, University of California, Davis School of \\ Medicine, 4860 Y Street, Suite 3740, Sacramento, CA 95817, \\ United States (e-mail: krshahlaie@ucdavis.edu).
}

\begin{abstract}
Objective Our primary objective was to retrospectively review our single institution experience using an anatomic multilayered repair of the retrosigmoid suboccipital craniotomy. Our secondary objective was to review the existing body of literature on the repair of this craniotomy and compare our outcomes to previous results.

Design Retrospective review of 25 consecutive patients undergoing repair for the retrosigmoid craniotomy.

Setting University of California Davis Medical Center (2010-2016).

Participants A total of 25 consecutive patients who underwent retrosigmoid craniotomy and repair. Exclusion criteria included patients who were under the age of

\section{Keywords}

- retrosigmoid craniotomy

- cranioplasty

- CSF leak

- headache

- repair

- skull base

- gasket seal

18 years.

Main Outcome Measures Main outcomes included incidence of postoperative headache, cerebrospinal fluid leak, and wound infections.

Results Postoperative headache was reported in two patients in this series (8\%). None of the patients in the series developed cerebrospinal fluid leak or wound infections. Mean follow-up period was 16 months.

Conclusion Our multilayered anatomic repair after retrosigmoid suboccipital craniotomy results in favorable clinical results and may help reduce the risks associated with this operation.
\end{abstract}

\section{Introduction}

The retrosigmoid suboccipital craniotomy is one of the most versatile neurosurgical corridors utilized to approach the cerebellopontine angle (CPA). ${ }^{1}$ Originally described by Harvey Cushing and Walter Dandy in 1917, this approach involves removal of occipital and temporal bone surrounding the asterion to provide access to the dura that is inferior and medial to the transverse and sigmoid sinuses. After completing the intracranial portion of the procedure, a variety of techniques have been described for the repair of the surgical defect. These techniques are associated with a 5 to $26.7 \%$ complication rate, which includes postoperative cerebrospinal fluid (CSF) leak, persistent suboccipital headaches, and wound infection. ${ }^{2-4}$

received

September 8, 2017

accepted after revision

December 2, 2017

published online

February 26, 2018

Various authors have described different repair techniques to reduce these complications and improve patient outcomes. Previously described strategies include techniques for dural repair and closure, craniotomy defect reconstruction, and soft tissue wound closure. ${ }^{2,4-6}$ We report our institutional experience performing a multilayered anatomic repair for the retrosigmoid suboccipital craniotomy that reconstructs the dura and entire bone defect.

\section{Methods}

\section{Study Population}

A retrospective chart review of 25 consecutive adult patients who underwent suboccipital retrosigmoid craniotomy by the primary investigator was performed. The electronic medical

(c) 2018 Georg Thieme Verlag KG Stuttgart · New York
DOI https://doi.org/ 10.1055/s-0038-1625976. ISSN 2193-6331. 
record and imaging studies were reviewed for the presence of CSF leak, persistent suboccipital headaches, and wound infections. The University of California, Davis Institutional Review Board approved this study.

\section{Suboccipital Retrosigmoid Craniotomy Repair Technique}

All patients in the study underwent a retrosigmoid approach in the lateral "park bench" position, using a linear incision within the hair-bearing scalp. A 14- to $18-\mathrm{mm}$ craniectomy was performed using a high-speed drill, with bone dust saved in antibiotic saline for subsequent repair (-Fig. 1A). If mastoid air cells were exposed, they were obliterated with bone wax during the approach and again prior to final repair. The dura was opened in a C-shape and reflected laterally toward the transverse sinus. After completing the intradural portion of the operation, the dura was primarily repaired using interrupted 4-0 braided nylon suture (-Fig. 1B). A collagen onlay was then placed on top of the dural repair (-Fig. 1C), followed by a small sheet of oxidized cellulose matrix (Surgicel, Ethicon; - Fig. 1D), then autologous bone chips/dust from the craniectomy ( - Fig. 1E, F), followed by a second outer layer of cellulose matrix to secure the bone chips/dust in place ( - Fig. 1C). A medium-sized titanium burr hole plate was then placed over the entire defect ( $\mathbf{- F i g . 1 H}$ ). Muscle layers and then deep fascia were reapproximated individually using 3-0 vicryl suture. The dermis was reapproximated using inverted 4-0 vicryl suture, and a 4-0 nylon suture was used to close the skin (-Fig. 2B). The wound was dressed with bacitracin ointment, a nonadhesive gauze covering, and tape. Dressings were left in place for 48 hours, then patients were instructed to shower daily and apply no ointments to the incision.

\section{Results}

\section{Patient Series}

Twenty-five consecutive patients underwent suboccipital retrosigmoid craniotomy with a mean follow-up time of 16 months. Two patients (8\%) reported persistent suboccipital headaches after surgery, with an average visual analog score of 6/10 (range: 4-8). None of the patients in this series developed CSF leak or wound infections (-Table 1). All patients reported a positive cosmetic outcome (-Fig. $\mathbf{2 C}$ ). Indications for retrosigmoid

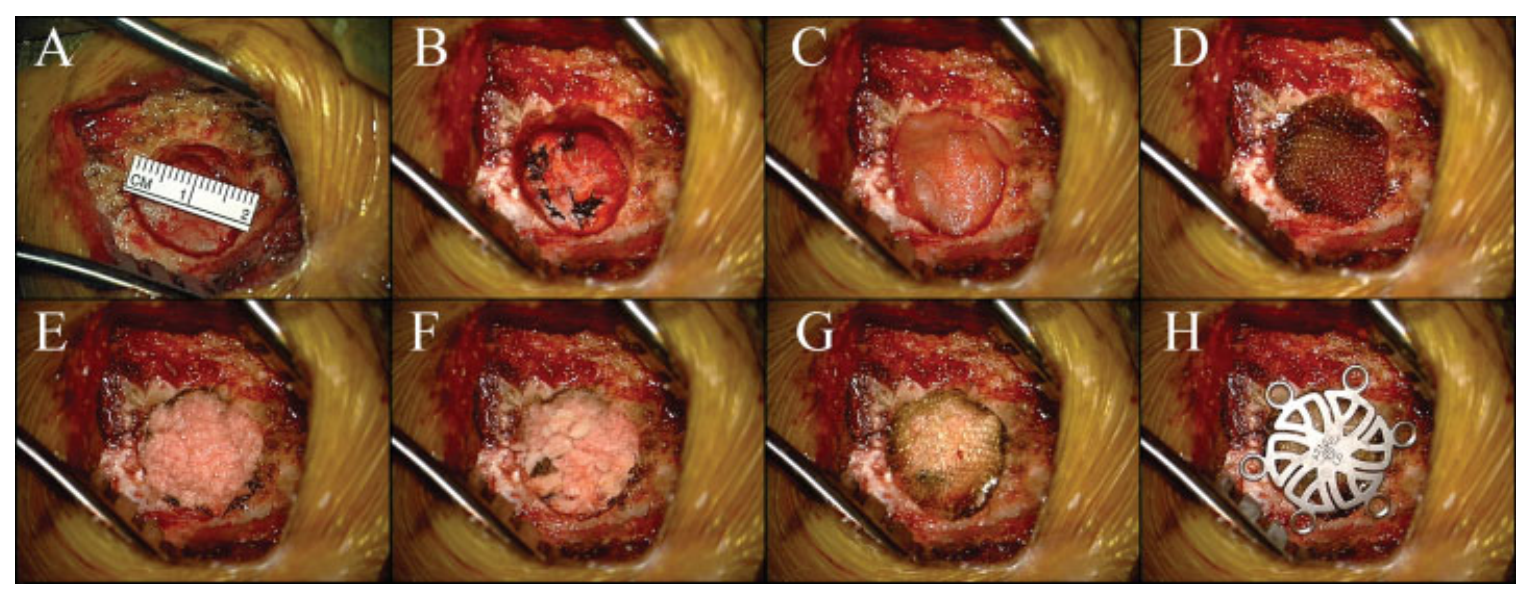

Fig. 1 Intraoperative photographs during right-sided retrosigmoid craniotomy. A 16-mm diameter craniotomy is performed using a high-speed drill (panel A). After completing the intradural portion of the operation, the dura is primarily repaired using interrupted $4-0$ braided nylon suture (panel B). A collagen onlay is then placed over this repair (panel C), followed by a small sheet of cellulose matrix that covers the entire defect cavity (panel D). Autologous bone dust and bone chips are then used to fill the defect (panels $E$ and $F$ ), and a second small sheet of cellulose matrix is placed over and around the bone packing to secure the contents (panel $\mathrm{G}$ ). A titanium burr hole cover plate is placed over the repair (panel $\mathrm{H}$ ) and secured using 4-mm self-tapping screws (not shown).
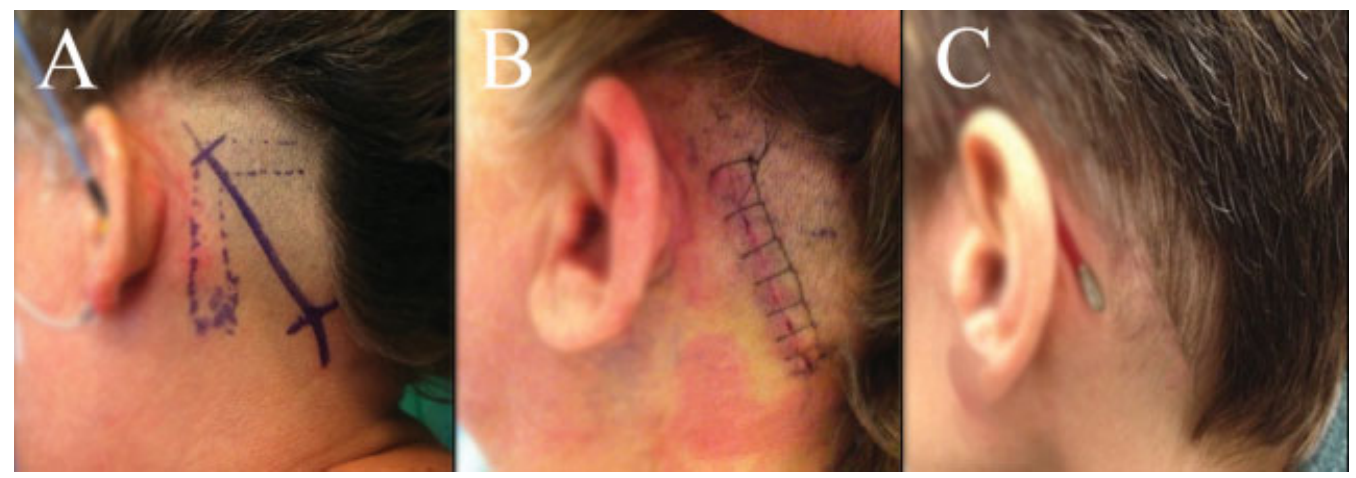

Fig. 2 A 5-cm linear incision is marked on the hair bearing portion of the scalp, starting at the approximate location of the transverse-sigmoid sinus (panel A). Nylon suture is removed on postoperative day 7 to 10 (panel B). Appearance of the incision site 2 months after surgery (panel C). 
Table 1 Summary of case series describing surgical repair technique and clinical outcomes after retrosigmoid craniotomy

\begin{tabular}{|c|c|c|c|c|c|c|c|}
\hline Author & $n$ & Surgical technique & $\begin{array}{l}\text { CSF } \\
\text { fistula }\end{array}$ & $\begin{array}{l}\text { Preop } \\
\text { headache }\end{array}$ & $\begin{array}{l}\text { Postop } \\
\text { headache }\end{array}$ & Meningitis & $\begin{array}{l}\text { Wound } \\
\text { infection }\end{array}$ \\
\hline $\begin{array}{l}\text { Samii } \\
\text { et } \mathrm{al}^{3}\end{array}$ & 1,000 & $\begin{array}{l}\text { Primary dural closure, unspecified } \\
\text { cranioplasty }\end{array}$ & $9.2 \%(92)$ & $\mathrm{nr}$ & $9 \%(90)$ & $\begin{array}{l}3 \%(30) \\
{[1.3 \% \text { Bac- }} \\
\text { terial, } \\
1.7 \% \\
\text { aseptic] }\end{array}$ & $3 \%(6)$ \\
\hline $\begin{array}{l}\text { Abolfotoh } \\
\text { et al }\end{array}$ & 432 & $\begin{array}{l}\text { Transmastoid retrosigmoid } \\
\text { approach, primary dural closure, } \\
\text { pericranium graft if necessary, } \\
\text { mastoid bone cranioplasty with } \\
\text { fat graft, hydroxyapatite bone } \\
\text { substitute, reattachment of } \\
\text { sternocleidomastoid, two-layer } \\
\text { skin closure }\end{array}$ & $6.7 \%(29)$ & $\mathrm{nr}$ & $2.7 \%(12)$ & $0.7 \%(3)$ & $\mathrm{nr}$ \\
\hline $\begin{array}{l}\text { Cardoso } \\
\text { et } \text { al }^{8}\end{array}$ & 240 & $\begin{array}{l}\text { Primary dural closure, fibrin glue } \\
\text { and cellulose polymer reinforce- } \\
\text { ment over primary dural closure, } \\
\text { bone cranioplasty, multilayered } \\
\text { muscle and skin closure }\end{array}$ & $5.8 \%(14)$ & $\mathrm{nr}$ & $\mathrm{nr}$ & $2.9 \%(7)$ & $\mathrm{nr}$ \\
\hline $\begin{array}{l}\text { Samii } \\
\text { et al }\end{array}$ & 200 & $\begin{array}{l}\text { Primary dural closure, methyl- } \\
\text { methacrylate cranioplasty, multi- } \\
\text { layered anatomical muscle and } \\
\text { skin closure }\end{array}$ & $2 \%(4)$ & $\mathrm{nr}$ & $0 \%$ & $0 \%$ & $1 \%(2)$ \\
\hline $\begin{array}{l}\text { Ling } \\
\text { et al }\end{array}$ & 60 & $\begin{array}{l}\text { Primary dural closure, fat graft } \\
\text { reinforcement, titanium mesh } \\
\text { cranioplasty }\end{array}$ & $0 \%$ & $\mathrm{nr}$ & $0 \%$ & $\mathrm{nr}$ & $\mathrm{nr}$ \\
\hline $\begin{array}{l}\text { Goodarzi } \\
\text { et al } \\
\text { (current } \\
\text { series) }\end{array}$ & 25 & $\begin{array}{l}\text { Primary dural closure using } 4-0 \\
\text { nylon suture, bone dust and } \\
\text { titanium plate cranioplasty, } \\
\text { layered closure of deep fascia, } \\
\text { layered closure of dermis and } \\
\text { epidermis with 3-0 nylon suture }\end{array}$ & $0 \%$ & $4 \%\left(1^{a}\right)$ & $8 \%(2)$ & $0 \%$ & $0 \%$ \\
\hline
\end{tabular}

Abbreviation: $\mathrm{nr}$, not reported.

${ }^{a}$ The patient was diagnosed with causalgia and migraine type headaches preoperatively. However, the patient, postoperatively, experienced new onset suboccipital headaches on the side of the craniotomy.

craniotomy included cerebellopontine angle and petroclival neoplasms, trigeminal neuralgia, hemifacial spasm, Meniere's disease, and congenital lesions ( - Fig. 3). The median operative time was 390 minutes with a rage of 140 to 785 minutes. Postoperative imaging was performed only in cases involving tumor resection to assess for gross total resection or in cases of acute neurologic deficits. - Fig. 4 demonstrates 24-hour and 6month postoperative CTs highlighting the bone dust craniotomy repair technique, without any signs of pseudomeningocele (-Fig. 4).

\section{Discussion}

The retrosigmoid suboccipital craniotomy is a common surgical approach to the lateral skull base of the posterior fossa. Despite its frequent utilization among neurosurgeons, there remains significant variability in the reconstruction technique used by different surgeons. Many groups have described their repair strategy, with a variety of associated complication rates ( - Table $\mathbf{1}$ ). In this study, we describe our surgical technique and report a complication rate that is consistent with previously described large series.

\section{Cranial Reconstruction Technique}

A key principle of postcraniotomy reconstruction is to reestablish anatomic barriers between the intracranial and extracranial compartments while maintaining normal physiology. ${ }^{7}$ The first step toward reestablishing these barriers is to achieve a watertight dural closure, which has been cited as the most important factor in reducing risk of CSF leak. ${ }^{1,3,4,7,8}$ Once a watertight dural closure is achieved, reconstruction of the craniotomy defect must be performed. This reconstruction serves as a barrier between the dura and the suboccipital muscles, and provides a rigid mechanical buttress to reinforce the dural repair. This rigid barrier can also be utilized to create a gasket effect that helps promote a more effective watertight seal. ${ }^{9}$ A complete cranial reconstruction must obliterate the epidural space, and soft tissue closure should similarly minimize the subgaleal compartments by apposing the soft tissues to the 


\section{Surgical Pathology of Retrosigmoid Craniotomies}

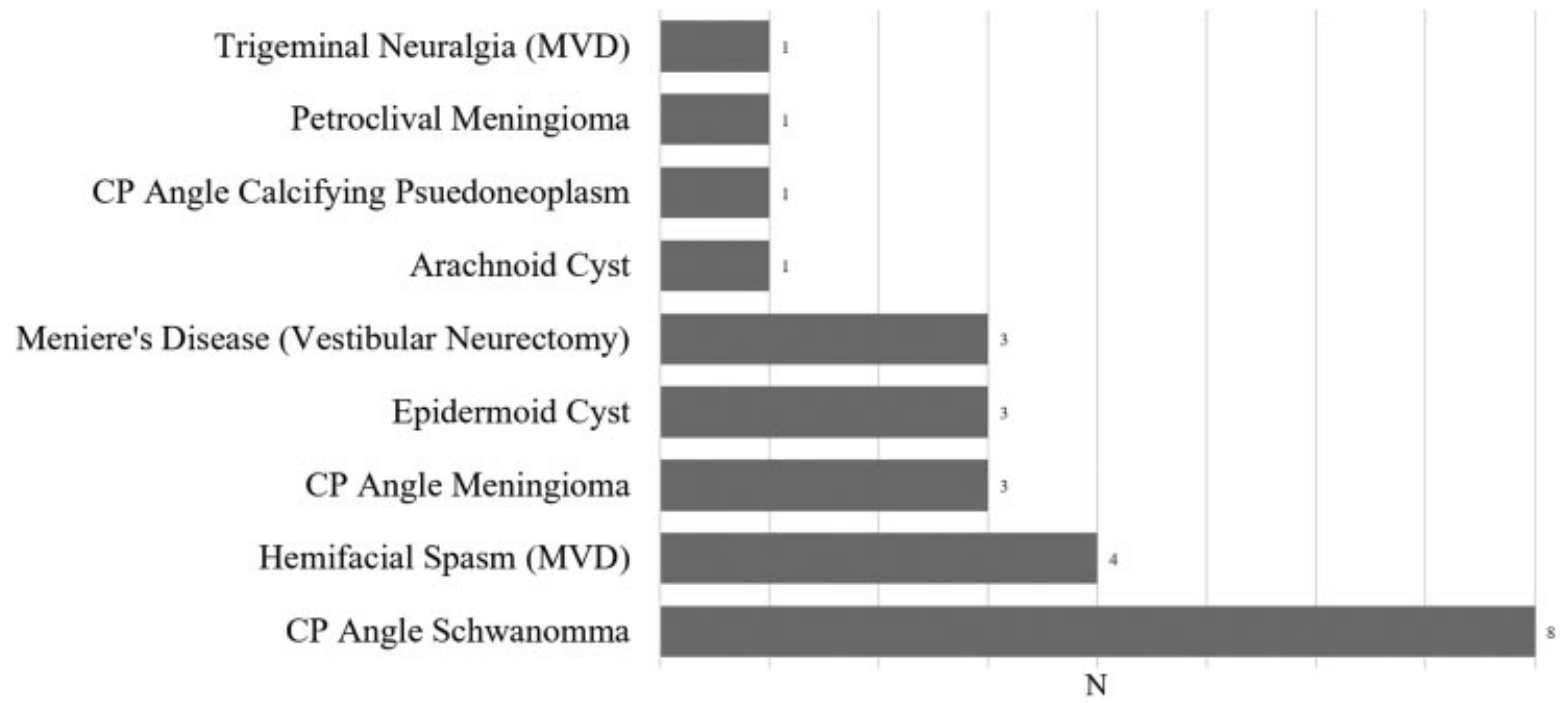

Fig. 3 A graphical representation of retrosigmoid craniotomy repairs in this series using the surgical pathology. CP, cerebellopontine; MVD, microvascular decompression. $\mathrm{N}$, number of patients.

outer table of the bony reconstruction. Finally, a durable skin closure must be performed as the last barrier in the reconstruction. ${ }^{1,3,7}$

These are the principles used in the surgical technique described in this article. A watertight dural closure is obtained with a braided, nonabsorbable suture followed by a collagen epidural onlay. This is supported by an overlying cranial reconstruction that fills the entire craniotomy defect with autologous bone dust and chips. The final cellulose sheet covering and titanium plate ensure that the autologous bone remains in place and provides additional support to the reconstruction. The titanium plate also prevents scarring between the overlying soft tissues and the dura, which has been implicated in suboccipital headache syndrome following retrosigmoid craniotomy. 8,10

\section{Cerebrospinal Fluid Leak}

Cerebrospinal fluid leak is a significant postoperative complication, which has been reported to occur in 0 to $26.7 \%$ of cases. ${ }^{4-7,9}$ Prevention of CSF leak is extremely important, as it increases the risk of meningitis and often requires additional procedures such as percutaneous drainage of

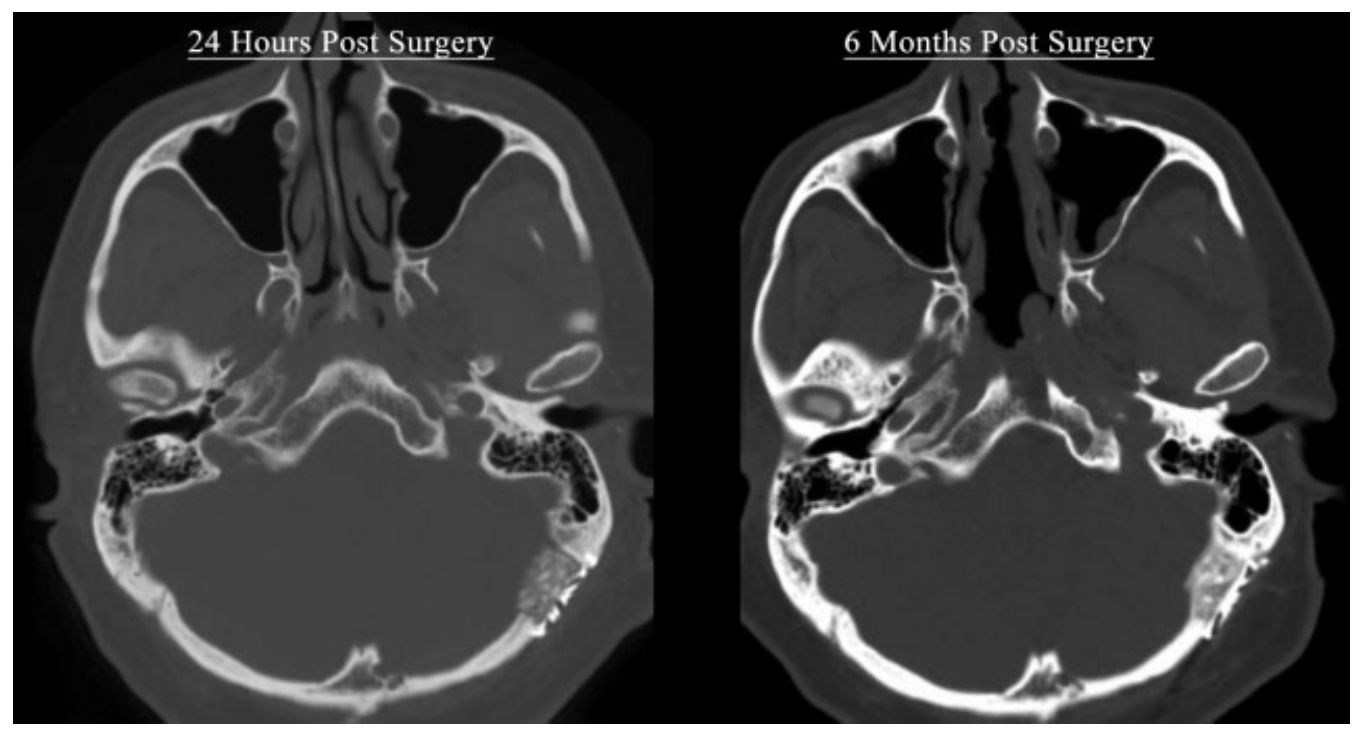

Fig. 4 CT sequences performed 24 hours postsurgery (left panel) and 6 months postsurgery (right panel), demonstrating a left retrosigmoid craniotomy reconstruction, without any noticeable pseudomeningocele. The custom bone dust cranioplasty remains within the craniotomy defect, providing a mechanical buttress to support the dural repair and prevent cerebrospinal fluid leak. There is robust bone remodeling overlying the previous craniotomy site 6 months after the repair is performed. CT, computed tomography. 
pseudomeningoceles, lumbar drain insertion, and surgical reexploration. $^{11,12}$ To address this complication, many authors have described reconstruction techniques that focus on achieving a watertight dural closure. For example, Samii et al reported a $2 \%$ incidence of CSF leak in a series of 200 patients closed with primary dural closure along with a pericranial flap. ${ }^{4}$ Cardoso et al reported a slightly higher incidence of $5.8 \%$ in a series of 240 patients, using a primary dural closure along with fibrin glue and cellulose matrix reinforcement. ${ }^{8}$ In a large series of 432 patients, Abolfotoh et al described CSF leak in $6.7 \%$ of patients who underwent primary dura closure and selected use of a pericranial tissue flap. ${ }^{6}$ These series highlight the importance of a meticulous dural closure, with possible extradural reinforcement, in preventing postoperative CSF leak.

In our series of 25 consecutive patients, we achieved primary dural closure and complete skull reconstruction in all cases and had no postoperative CSF leaks. Our results reinforce the importance of dural closure, and suggest that obliterating the epidural space and reconstructing the overlying bone defect with a rigid construct may be of added benefit. Establishing a mechanical buttress may help to absorb CSF pulsations and can create a gasket seal, reducing the likelihood of CSF leak. ${ }^{1,3,4,9}$ An anatomic repair that includes reconstruction of the dura as well as reconstruction of the rigid anatomy that normally occupies the epidural space may be a prudent strategy to reduce CSF leak in posterior fossa surgery.

\section{Headaches}

Persistent suboccipital headaches are a frequent complication of the retrosigmoid suboccipital craniotomy, with a reported incidence as high as $73 \% .^{10,13,14}$ Virtually, all patients experience some degree of discomfort surrounding a craniotomy operative site immediately after surgery, but persistent suboccipital headaches are a chronic condition that can last for months to years. Management may require chronic analgesics and long-term follow-up, resulting in increased cost of care and poor patient satisfaction. ${ }^{10}$ Although the exact pathophysiology of these headaches has yet to be elucidated, recent reports have demonstrated a reduction in their incidence with the use of cranioplasty, duraplasty, and the conservation of anatomic myocutaneous planes. $^{10,14}$

Current theories to explain the underlying pathophysiology of these headaches include (1) excessive dural stretch and tension, (2) myocutaneous-dural scarring secondary to loss of normal tissue barriers, and (3) dural irritation secondary to the use of sealants such as fibrin glue. ${ }^{10,11,14-16}$ Many authors have proposed techniques to ameliorate these possible underlying mechanisms with some success. For example, some authors have advocated the use of bone cranioplasty, methymethacrylate cranioplasty, hydroxyapatite cranioplasty, or titanium mesh, reporting headache incidence ranging from 0 to $9 \%^{3,4,13}$ In these series, the use of synthetic cranioplasty material or titanium mesh coincides with a lower rate of headaches as compared with bone cranioplasty. Additionally, a multilayered soft tissue closure may also be an important factor in reducing the risk of postoperative headaches, since the posterior fossa dura and suboccipital muscles are rich in blood supply and innervation. ${ }^{11,15}$

In our series, 2 of 25 patients (8\%) reported persistent postoperative headaches during the mean follow-up period of 16 months, with an average severity of 6/10 on the visual analog scale. This is consistent with previous reports (-Table 1) and suggests that a repair technique that reestablishes anatomic separation between the dura and extracranial soft tissues may be an important factor. Our technique includes recreating this mechanical barrier by using autologous bone dust and a titanium plate, avoiding the need for artificial bone substitute materials. In a small subset of patients who underwent redo surgery for tumor recurrence, there was complete reconstitution of the craniotomy defect with autologous bone and no evidence of myodural scar formation. This suggests that the repair technique described in this series is an effective strategy to reconstruct normal anatomic planes following retrosigmoid craniotomy.

\section{Conclusion}

We present an anatomic technique for repair of the suboccipital retrosigmoid craniotomy using: (1) primary watertight dural repair, (2) collagen epidural onlay graft, (3) autologous bone dust cranial reconstruction reinforced with a titanium plate, and (4) layered soft tissue closure. This technique was associated with a low incidence of common postoperative complications and may be an effective strategy to optimize patient outcomes following retrosigmoid craniotomy.

\section{Note}

The contents of this manuscript have been submitted for consideration as an electronic poster to the North American Skull Base Society conference to be held on February 14, 2018 in Coronado, California.

\section{References}

1 Schaller B, Heilbronner R, Pfaltz CR, Probst RR, Gratzl O. Preoperative and postoperative auditory and facial nerve function in cerebellopontine angle meningiomas. Otolaryngol Head Neck Surg 1995;112(02):228-234

2 Cueva RA, Mastrodimos B. Approach design and closure techniques to minimize cerebrospinal fluid leak after cerebellopontine angle tumor surgery. Otol Neurotol 2005;26(06):1176-1181

3 Samii M, Matthies C. Management of 1000 vestibular schwannomas (acoustic neuromas): the facial nerve-preservation and restitution of function. Neurosurgery 1997;40(04):684-694, discussion 694-695

4 Samii M, Gerganov V, Samii A. Improved preservation of hearing and facial nerve function in vestibular schwannoma surgery via the retrosigmoid approach in a series of 200 patients. J Neurosurg 2006;105(04):527-535

5 Ansari SF, Terry C, Cohen-Gadol AA. Surgery for vestibular schwannomas: a systematic review of complications by approach. Neurosurg Focus 2012;33(03):E14

6 Abolfotoh M, Dunn IF, Al-Mefty O. Transmastoid retrosigmoid approach to the cerebellopontine angle: surgical technique. 
Neurosurgery 2013;73(1, Suppl Operative) ons16-ons23, discussion ons23

7 Richmon JD, Yarlagadda BB, Wax MK, Patel U, Diaz J, Lin DT. Locoregional and free flap reconstruction of the lateral skull base. Head Neck 2015;37(09):1387-1391

8 Cardoso AC, Fernandes YB, Ramina R, Borges G. Acoustic neuroma (vestibular schwannoma): surgical results on 240 patients operated on dorsal decubitus position. Arq Neuropsiquiatr 2007;65 (3A, 3a):605-609

9 Garcia-Navarro V, Anand VK, Schwartz TH. Gasket seal closure for extended endonasal endoscopic skull base surgery: efficacy in a large case series. World Neurosurg 2013;80(05):563-568

10 Schaller B, Baumann A. Headache after removal of vestibular schwannoma via the retrosigmoid approach: a long-term followup-study. Otolaryngol Head Neck Surg 2003;128(03):387-395

11 Ling PY, Mendelson ZS, Reddy RK, Jyung RW, Liu JK. Reconstruction after retrosigmoid approaches using autologous fat graftassisted Medpor Titan cranioplasty: assessment of postoperative cerebrospinal fluid leaks and headaches in 60 cases. Acta Neurochir (Wien) 2014;156(10):1879-1888

12 Bryce GE, Nedzelski JM, Rowed DW, Rappaport JM. Cerebrospinal fluid leaks and meningitis in acoustic neuroma surgery. Otolaryngol Head Neck Surg 1991;104(01):81-87

13 Harner SG, Beatty CW, Ebersold MJ. Headache after acoustic neuroma excision. Am J Otol 1993;14(06):552-555

14 Jackson CG, McGrew BM, Forest JA, et al. Comparison of postoperative headache after retrosigmoid approach: vestibular nerve section versus vestibular schwannoma resection. Am J Otol 2000;21(03):412-416

15 Koperer H, Deinsberger W, Jödicke A, Böker DK. Postoperative headache after the lateral suboccipital approach: craniotomy versus craniectomy. Minim Invasive Neurosurg 1999;42(04): $175-178$

16 Ln S, Wb G, Dc W. The best treatment for vestibular schwannoma (acoustic neuroma): microsurgery or radiosurgery? Am J Otol 1996;17(04):676-682 